\title{
Alveolar Bone Grafting - A Summary of History and Current Literature on the Technique
}

\author{
Karthika Manoj Nambiar1, Ranjit Kamble², Kritika P. Suroliya ${ }^{3}$, Monika M. Ahuja ${ }^{4}$, Pallavi S. Daigavane ${ }^{5}$, Savi M. Vora ${ }^{6}$
}

\begin{abstract}
${ }^{1}$ Department of Orthodontics and Dentofacial Orthopaedics, Sharad Pawar Dental College, Datta Meghe Institute of Medical Sciences, Wardha, Maharashtra, India. ${ }^{2}$ Department of Orthodontics and Dentofacial Orthopaedics, Sharad Pawar Dental College, Datta Meghe Institute of Medical Sciences, Wardha, Maharashtra, India. ${ }^{3}$ Department of Orthodontics and Dentofacial Orthopaedics, Sharad Pawar Dental

College, Datta Meghe Institute of Medical Sciences, Wardha, Maharashtra, India. ${ }^{4}$ Department of Orthodontics and Dentofacial Orthopaedics, Sharad Pawar Dental College, Datta Meghe Institute of Medical Sciences, Wardha, Maharashtra, India. ${ }^{5}$ Department of Orthodontics and Dentofacial Orthopaedics, Sharad Pawar Dental College, Datta Meghe Institute of Medical Sciences, Wardha, Maharashtra, India. ${ }^{6}$ Department of Orthodontics and Dentofacial Orthopaedics, Sharad Pawar Dental College, Datta Meghe Institute of Medical Sciences, Wardha, Maharashtra, India.
\end{abstract}

\section{ABSTRACT}

\section{BACKGROUND}

Cleft lip and palate is a common condition affecting thousands of children in India and overseas. With an incidence of 1 in 800 live births, these cleft lip and cleft palate patients face numerous aesthetic as well as functional challenges. The condition goes untreated in many scenarios, or patients do not receive adequate treatment due to various reasons like lack of awareness, lack of specialist dentists etc. leading to permanent facial deformity with significant deterioration of quality of life. There have been many changes in the management of alveolar cleft in the past 100 years. Documentation of the first cleft lip repairs dates back to $400 \mathrm{BC}$, and was performed by Hippocrates, while the first cleft velum repair was done for the first time by a French dentist, Monnier, in 1764. The treatment protocol for the same has been upgraded with time, with better understanding of the anatomy and pathophysiology of the condition, and for better results to the patients. Alveolar bone grafting (ABG) is now becoming an integral part of managing cleft patients. There still isn't a fixed and widely accepted protocol for ABG in the management of cleft patients, but there are various opinions of researchers around the world regarding the indications of bone grafting, the type of grafting (primary or secondary) to be employed, timing of grafting, the source of bone graft and use of various bone graft substitutes in the procedure. An increasing value of multidisciplinary approach, including maxillofacial surgeons and orthodontists, towards managing such patients, is helping improve the outcome of such patients, and hence easing the overall treatment duration for the patient and relatives. Hence, through this article, we aim to shed some light over the evolvement and current place of alveolar bone grafting in treating cleft lip and palate patients. The anatomy of involved parts, types and indications of ABG, clinical evidences on the timing of the surgery, future evaluation, results and complications, and orthodontic treatment have been mentioned in this article.

\section{KEY WORDS}

Alveolar Bone Graft, ABG, Cleft Lip, Cleft Palate, Maxillofacial Surgery, Orthodontics
Corresponding Author: Karthika Manoj Nambiar, T-24, Shalinta PG Girls Hostel, DMIMSU, Sawangi Meghe, Wardha-442001, Maharashtra, India. E-mail: karthikanambiar@ymail.com

DOI: $10.14260 /$ jemds/2020/576

How to Cite This Article: Nambiar KM, Kamble R, Suroliya KP, et al. Alveolar bone grafting- a summary of history and current literature on the technique. J Evolution Med Dent Sci 2020;9(36):2652-2657, DOI: $10.14260 /$ jemds $/ 2020 / 576$

Submission 11-05-2020, Peer Review 11-07-2020, Acceptance 17-07-2020, Published 07-09-2020.

Copyright (C) 2020 JEMDS. This is an open access article distributed under Creative Commons Attribution License [Attribution 4.0 International (CC BY 4.0)] 
Cleft lip and Palate are one of the most common congenital craniofacial deformities seen in children. ${ }^{1}$ Patients with cleft lip and palate (CLP) suffer from several aesthetic and functional challenges. ${ }^{2}$ Approximately every $1 / 800$ live births are born with a Cleft lip (CL). This may or may not be accompanied by a cleft palate (CP). ${ }^{3}$

Alveolus with a bony defect, which may also be termed as Alveolar cleft (AC), is a common congenital defect. This forms up to $75 \%$ of CL or CL and CP patients. As poor as it may be, but the current literature related to cleft, points its cause to be having multiple factors, including genetic and environmental causes. The development of dentition may be affected by AC, leading to alveolar segment collapse. ${ }^{4}$

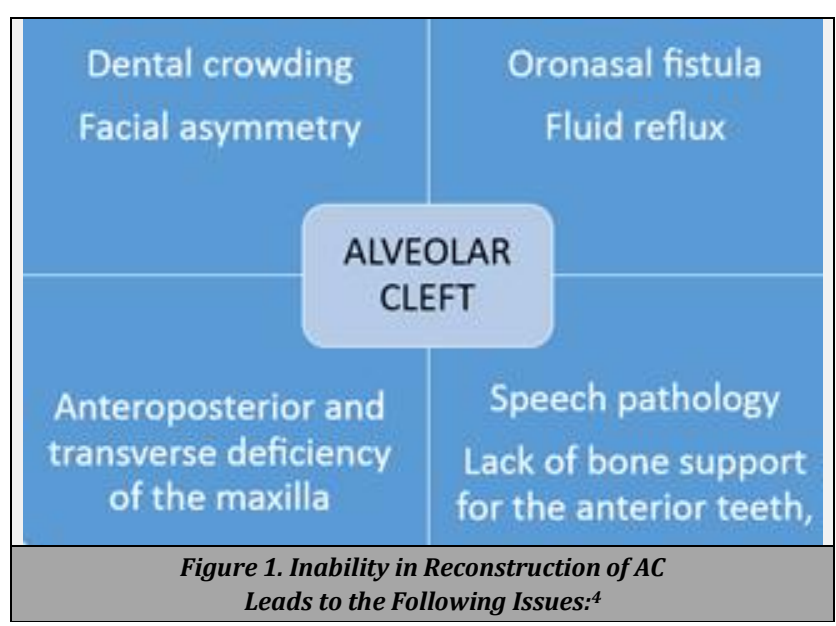

Oronasal fistula having symptoms in a patient, of alveolar process with an osseous defect and/or bone insufficiency hindering tooth eruption or orthodontic treatment or prosthodontic rehabilitation in this area, can be contemplated for Alveolar bone grafting (ABG) ${ }^{4}$

This is now widely accepted that ABG is an integral to cleft treatment. This refers to the bony approximation of the defect in alveolar bone that is needed to form normal upper dental arch. After Boyne and Sands' study describing secondary ABG, this technique has become the popular method of choice and holds a unique place in the entire system of cleft and palate treatment. ${ }^{4}$

Given the comparatively high prevalence of lip and palate clefts, there are only a few studies on these patients' treatment. In the present review, the literature on alveolar bone grafting is examined concerning timing, technique, bone sources, various methods to determine the effectiveness of the graft and the complications are discussed.

\section{Development and Anatomical Features of Alveolus}

Alveolar bone is a part of the primary palate. It is developed around the $5^{\text {th }}$ to $6^{\text {th }}$ week of intrauterine life by fusion of maxillary prominences. The nose, lip, prolabium and premaxilla are the parts arising from the primary palate, all being in front of the incisive foramen. The Word alveolus originated in Latin.

It defines a tiny cavity or space. Dental alveolus is a cavity/socket for the tooth. The tooth sockets are located at the maxillary alveolar process and this forms the main concern regarding the functionality in alveolar clefting. The teeth and the alveolar bone are joined by periodontal ligaments. In lack of the necessary bone stock in the alveolar cleft, needed for eruption, the permanent teeth seize to be unsustainable. The typical eruption into the AC space is seen by the maxillary canine, while the lateral incisor eruption occurs, either next to or even in the cleft. The eruption of these teeth occur mostly in the age range of seven to twelve years. The most suitable time for $A B G$ is before the involved tooth erupts. Hence to avoid losing a tooth by its eruption into cleft alveolus, taking dental $\mathrm{x}$-rays early in life is advicable. ${ }^{5}$

\section{Historical Background}

The first reconstruction of cleft lip dates back to Hippocrates (400 BC) and Galen (150 AD). Breakthroughs in the procedure and results have been occurring over the years. Cleft velum's first repair was done in 1764 by a dentist from France, Le Monnier. The cleft alveolus is a less prominent part of the cleft perpetuity. Also, the importance of $A B G$, which is a relatively new procedure, is responsible for the lack of many historical references to AC repair. In 1901, Von Eiselsberg performed the first ABG, using an osteocutaneous flap with a pedicle, Drachter in 1914, did the first successful ABG, using a graft from the tibia, including periosteum. In the two decades of the 1950s and 1960s, primary ABG, within the first few months of life, started becoming popular.

Most of the dental professionals and surgeons during the 1950s and 1960s began employing primary bone grafting of the alveolus in the early months of life. Initially, it was often conducted while the patient had deciduous teeth, to avoid maxillary collapse. ${ }^{5}$ Pickrell et al. in the year 1968, presented that primary grafts did not grow proportionately with the skull. They also found out that the teeth didn't persistently erupt in the primary ABG grafts. And hence, secondary grafting, in the time of mixed dentition, became famous. To date, there are various beliefs amongst dentists around the world regarding the following points-

1. Timing of grafting during the second period

2. Using orthodontic appliances before the surgery.

3. Surgical procedure and graft source,

4. Outcome analysis of $A B G .^{3}$

\section{ABG Goals}

1. Vestibular \& Oronasal fistula closure

2. Providing enough bone stock for the permanent teeth (central incisor of maxilla, lateral incisor and canine)

3. To make a base for the nasal skeleton

4. To make a bony architecture that is required for nasolabial muscles reconstruction in symmetry.

5. To build a floor for nasal airway which is functional

6. Providing enough bone stock for the use of dental implants (osseointegrated)

\section{Primary Bone Graft}

Many dental surgeons were performing primary and early secondary ABG in the 1950s and 1960s. 


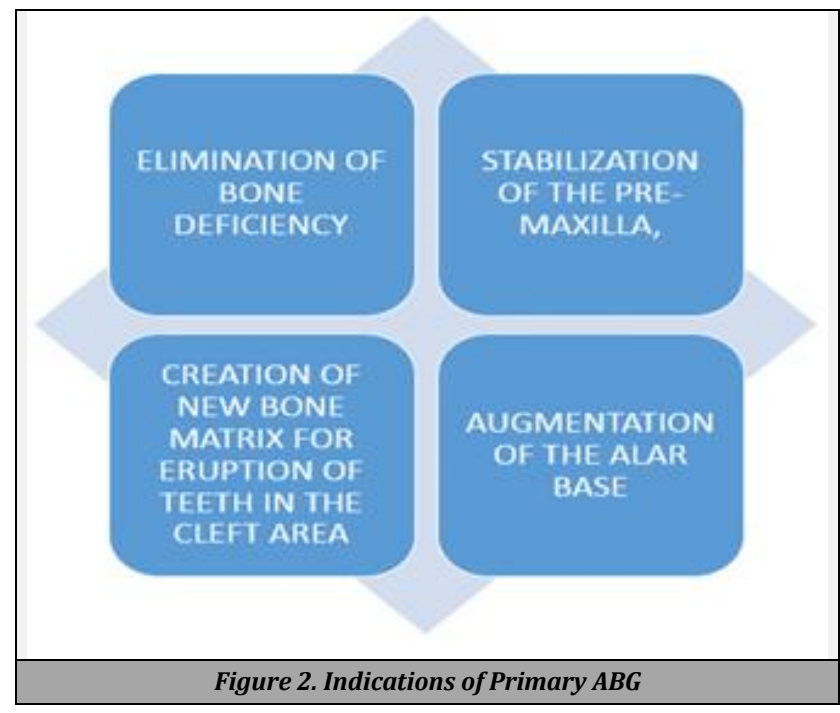

The maxillary growth was even expected to normalize or get stimulated from these procedures. But the literature after 1964 suggests that these early graft surgeries caused serious derangements in the growth of facial bones. The vomeropremaxillary suture technique was found to be the cause of this growth issue. Leaving a few centers, most others do not perform primary $\mathrm{ABG}$ anymore.

\section{Secondary Bone Graft}

Secondary bone grafting (SBG), became an established procedure after abandoning the primary. ${ }^{5}$

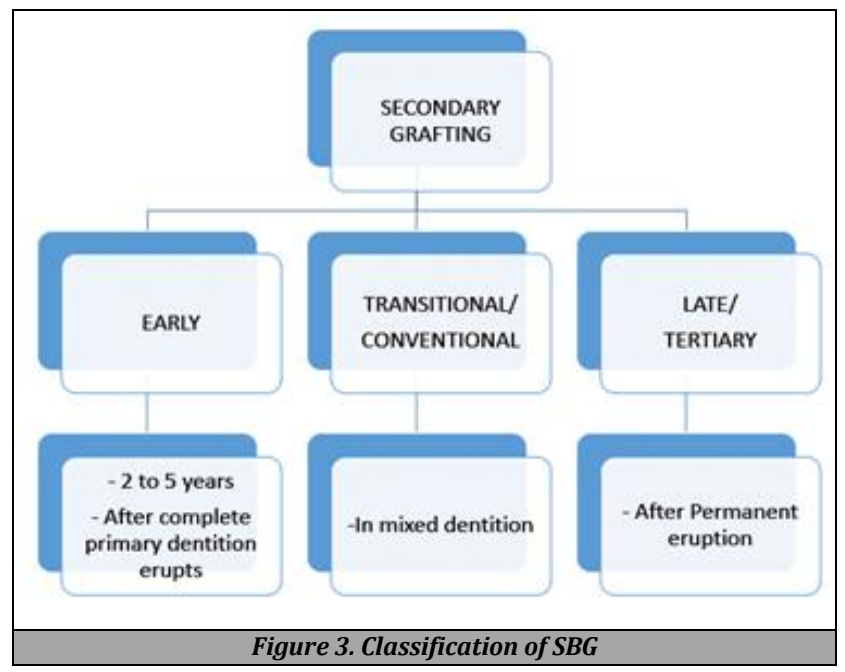

Preventing food retention, and hence betterment of oral hygiene and avoiding inflammation, is the role of SBG. ${ }^{6}$ This procedure also gives stability to the maxillary portion and enhances facial aesthetics and symmetry by stimulation eruption, orthodontic teeth movement, nasal support and projection with sufficient alveolar bone support. ${ }^{7}$ According to a report by Semb et al., there isn't any change in the Anteroposterior or vertical maxillary growth pattern. ${ }^{8}$ Also there is minimal difference in cephalograms of ABG patients and nonABG patients. ${ }^{9}$ As accepted as it may be, SBG also has arguments unresolved: (i) Age for SBG (Bergland 1986) ${ }^{10}$ (ii) Graft type and site for taking the graft (Freihofer1993) ${ }^{11}$
(iii)Orthodontic treatment before $\mathrm{ABG}$, and its functional results (Long 1995; Kindelan 1999) ${ }^{12}$. Only a 58\% success rate was described in children undergoing grafting, relating to optimal age or ethnicity. ${ }^{13,14}$ Substandard outcomes and controversies around SBG creates a need for future researches to enhance the results of this procedure.

\section{Timing of Grafting}

A notable study in primary bone grafting was by Boyne and Sands, which advocated doing ABG in mixed dentition. ${ }^{15}$ But the study faced opposition due to deranged facial growth pattern which was observed after primary ABG. The growth of anterior maxilla occurs till 8-9 years of age 16 and hence it was suggested to delay ABG till about that age, as that wouldn't cause any growth disturbances in facial bone. And studies in the coming years proved the same point.8,17 Some dentists still suggested $A B G$ to be done earlier in life to allow eruption of permanent central and lateral incisors. ${ }^{18,19}$ It has been suggested that it prevents the recession of gingiva that is often seen on the central incisor on the cleft side and allow a better chance of developing root for the lateral incisors, if they are present. The time for grafting and the bone growth followed by the surgery, still to be formally explored. A wider time range is now accepted, around 7 years or earlier for patients with a useful lateral incisor (28-37\%).10,19 It can also be done just before the canines erupt, as then the lateral incisors are expendable or if the lateral incisors are congenitally missing. It is proposed that delay in grafting in such cases may decrease canine impaction. ${ }^{20}$

\section{Sources of Bone Grafting}

It is of the utmost concern that the donor tissue survives in grafting surgeries. Cortical and cancellous both bones can be used as grafts, but cancellous bone is a better option due to cell transfer and revascularization as a result of osteoinduction and osteoconduction. Many substances have been used in the treatment of AC, like bone grafts (autologous and allogeneic), xenogenic bone, rhBMP and growth factors. But fresh autologous cancellous bone graft is considered the ideal source. $^{21}$

\section{Iliac Crest}

Iliac bone is the most commonly used bone to harvest a graft. The pros for it are: (i) easy to take graft, (ii) Sufficient amount of graft can be harvested, (iii) Cleft can be prepared at the same time by another surgeon. But the downside of this site is: (i) Scar formation, (ii) pain after surgery, (iii) Patient is allowed to move after a delay, and (iv) risk of injury to a cutaneous nerve. These complications can be reduced by using a small incision, minimal elevation of muscles, thorough hemostasis, satisfactory pain control, and early ambulation. ${ }^{7}$

\section{Cranium}

Less bony resorption, less pain and a hidden scar are the advantages of using cranium. But long surgical time, risk of hematoma, seroma, dura exposure or tear and CSF leak make it a reserved option. ${ }^{7}$ 


\section{Tibia}

Tibia is a graft that has minimal bleeding, post-op pain, time of operation, scar, and smaller hospital stay. But many reports are focused on collecting relatively small quantities of graft in adults, and if more quantity is required, both the legs might be needed to harvest. In children there may be epiphyseal injury leading to growth disturbances. ${ }^{22}$

\section{Mandibular Symphysis}

It shares the same origin as that of the maxilla. Mandible being a membranous bone, has a low resorption and higher revascularization rate. The process of harvesting graft and grafting can both be done in the same surgical field, making less post-op discomfort and early discharge of the patient. But there is a risk of nerve injury, injury to root of canine or incisor. Also the bone quantity harvested will depend on the growth of the mandible. ${ }^{23}$

\section{Bone Graft Substitutes}

Many allogeneic bones can be used as graft substitutes in ABG. Demineralized freeze-dried bone (DFDB) have more osteoinductive property, while Freeze-Dried Bone (FDB), a mineralized bone, has more osteoconductive property. ${ }^{24}$ Sometimes they are used together to replace autologous bone graft. The pros of these substitutes is, no complications related to harvesting graft. But the risk of infections, transfer of diseases and compatibility issues have been documented. ${ }^{25} \mathrm{At}$ times a combination of hydroxyapatite (HA), tricalcium phosphate (TCP) and recombinant human bone morphogenic protein (rhBMP) are used, but there is a risk of carcinogenesis due to overgrowth. ${ }^{26}$ Some recent literature presents the use of biologics such as platelet-rich plasma (PRP) and plateletrich fibrin (PRF) with bone grafting, but these aren't widely used. ${ }^{27}$ Oral surgeons have used rhBMP in ABG and have shown better outcomes than autologous iliac graft, but the bone volume left in this procedure is less. ${ }^{28}$ Literature supports DFDB and rhBMP use in combination, giving satisfactory results.

However, most studies using the Demineralized bone matrix and rhBMP have reported acceptable results. Francis et al. also reported that DFDB and rhBMP can be used as a replacement for iliac crest graft. ${ }^{29}$

\section{Orthodontic Treatment ${ }^{30}$}

Orthodontic treatment is discussed after assessing the stage of tooth eruption in the cleft area. Pre-op orthodontic treatment is required if alveolar ridges are not aligned and teeth are in an unacceptable position. It is also required when the ridge blocks the cleft area entry, here pre-op orthodontic treatment is used to expand the arch and ease the access during surgery. It should be taken into consideration that the central incisors near the cleft have a thin bony septa. Two-three months before the surgery, the deciduous teeth which may cause interference with grafting should be removed as it is found that removal of these teeth during the grafting procedure leads to less remaining bone and persistent retraction of the gingiva.
This can be explained by the presence of osteoresorptive cells and bone resorption suited environment. Carries should be dealt with, removal or conservatively, as good oral hygiene adds to the outcome of grafting.

\section{Methods to Assess Success of ABG}

The result monitoring should be accurate and the ideal scale should be able to make out failure chance much before the eruption of teeth in the cleft area, as revision surgery per se lead to increased failure rates. Out of the many scales proposed in the past, the one proposed by Bergland et al. (1986) is still the gold standard. It compares interdental septum with the normal side.

\begin{tabular}{|cc|}
\hline Type & Septal Height \\
I & Normal \\
II & At least three-quarters of normal \\
III & Less than three-quarters of normal \\
IV & Absence of a continuous bony bridge \\
\hline Table 1. Scale by Bergland for Assessment of Alveolar Bone Grafting \\
\hline
\end{tabular}

A 4-point scale was developed by Kinderlan et al. (1997) to evaluate the area of bony fill.

Kinderlan et al. (1997) used a four-point scale to assess the area of bony fill. Long et al. (1995) gave the concept of expressing results in the percentage of bone which covers the roots next to the cleft, which was calculated after tracing the bony contour. A comparison between computed tomography and dental radiographs was used by Rosenstein et al. (1997). Ultrasonography was used by Lawson and Jones (1997), and Witherow et al stated about the use of the Chelsea scale.

\begin{tabular}{|c|c|}
\hline Group & Bone Tissue \\
\hline A & $\begin{array}{l}\text { At the amelocemental junction and at least } 75 \% \text { of both roots covered } \\
\text { with bone }\end{array}$ \\
\hline B & In the amelocemental junction and in at least $25 \%$ of both roots \\
\hline $\mathrm{C}$ & Across at least $75 \%$ of the cleft roots from an apical direction \\
\hline D & Across at least $50 \%$ of both roots from an apical to coronal direction \\
\hline E & $\begin{array}{l}\text { A bridge like bone tissue in any area of the cleft except apically and } \\
\text { coronally }\end{array}$ \\
\hline $\mathrm{F}$ & $25 \%$ or less across both roots from an apical direction \\
\hline & Table 2. The Chelsea Scale: ${ }^{31}$ \\
\hline
\end{tabular}

But these assessment tools had their cons. The Bergland scale required the canine to erupt and hence cannot be used to evaluate failure in mixed dentition. Also, a cleft having a cent percent bone and one having less amount of bone at the usual interdental septum stage, cannot be differentiated using this scale.

The Kinderlan method requires anterior maxillary occlusal radiograph and does not tell about the part of bone within the cleft. The long scale requires high-quality radiographs, is time taking and does not specify the position of the bone. The Kinderlan et al. (1997) method measures bone area but does not describe the position of the bone in the cleft and is described as requiring an upper anterior occlusal radiograph. The Long et al. (1995) scale also expresses the area of bone without specifying its position. It requires very good-quality radiographs and is time-consuming. Bone placed in the coronal region is more essential than the apical region, especially if fifty percent or less of the AC is occupied with mature graft. ${ }^{32}$ 

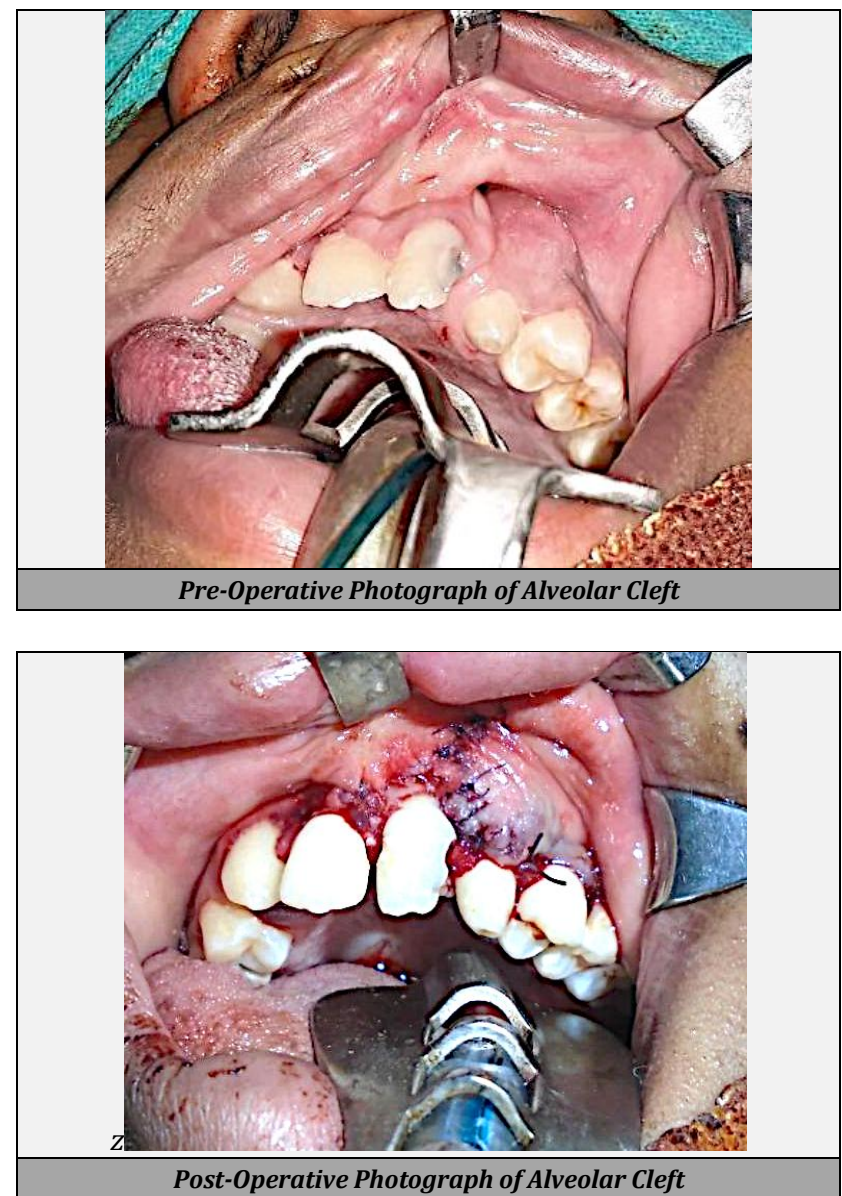

\section{Complications}

Exposure of ABG may occur by increased tension or trauma in the recovering phase after the operation. Minor of the above complication can be managed conservatively but the exposure of the bone graft is to be avoided at any cost. The resorption of the graft and notching o the alveolus can occur even in an overly packed graft. Revision surgery may be needed in about $5 \%$ of the cases. ${ }^{33}$

\section{CONCLUSIONS}

Cleft lip and palate are an anomaly which may be psychologically stressful for the family and debilitating for the patient. ${ }^{34}$ Treatment goal for cleft lip and palate (CLP) patients is to restore the normal anatomy of the affected structures. ${ }^{35}$ The cleft alveolus component of the oral cleft deformity is addressed with a separate surgical stage. ${ }^{36}$

There have been many changes in the management of alveolar cleft in the past 100 years. Alveolar bone grafting with autologous graft harvested from the iliac crest, in mixed dentition age of 6 - 11 years, still stays as the most accepted method. Bone substitutes have also gained popularity in the recent years.

$A B G$ is preferably done after the central incisors erupt in the cleft area, to achieve the best outcome, especially for space closure. If lateral incisors are present, $A B G$ should be considered for their eruption. If the lateral incisor eruption in the bone graft occurs, they can be used for space closure. Surgical skill is also important for the long term and favourable functional outcome. In the management of CL and CP patients, Alveolar bone grafting should be considered as the mainstay treatment option. ABG carries a significant benefit to the patient, both functionally and aesthetically. Alveolar bone grafting should be identified as an essential part of $A B G$ management and not just an adjuvant. More clinical research is welcome in enhancing our current understanding of the topic, to keep improving the quality of treatment being provided to cleft lip and palate patients.

Financial or Other Competing Interests: None.

\section{REFERENCES}

[1] Kasatwar A, Borle R, Bhola N, et al. Prevalence of congenital cardiac anomalies in patients with cleft lip and palate - its implications in surgical management. J Oral Biol Craniofac Res 2018;8(3):241-4.

[2] Karia H, Shrivastav S, Karia AK. Three-dimensional evaluation of the airway spaces in patients with and without cleft lip and palate: a digital volume tomographic study. Am J Orthod Dentofacial Orthop 2017;152(3):37181.

[3] Weissler EH, Paine KM, Ahmed MK, et al. Alveolar bone grafting and cleft lip and palate: a review. Plast Reconstr Surg 2016;138(6):1287-95.

[4] Guo J, Li C, Zhang Q, et al. Secondary bone grafting for alveolar cleft in children with cleft lip or cleft lip and palate. Cochrane Database Syst Rev 2011;(6):CD008050.

[5] Coots BK. Alveolar bone grafting: past, present, and new horizons. Semin Plastic Surg 2012;26(4):178-83.

[6] Daw JL, Patel PK. Management of alveolar clefts. Clin Plast Surg 2004;31(2):303-13.

[7] Kang NH. Current methods for the treatment of alveolar cleft. Arch Plast Surg 2017;44(3):188-93.

[8] Semb G. Effect of alveolar bone grafting on maxillary growth in unilateral cleft lip and palate patients. Cleft Palate J 1988;25(3):288-95.

[9] Chang HP, Chuang MC, Yang YH, et al. Maxillofacial growth in children with unilateral cleft lip and palate following secondary alveolar bone grafting: an interim evaluation. Plast Reconstr Surg 2005;115(3):687-95.

[10] Bergland O, Semb G, Abyholm FE. Elimination of the residual alveolar cleft by secondary bone grafting and subsequent orthodontic treatment. Cleft Palate J 1986;23(3):175-205.

[11] Freihofer HPM, Borstlap WA, Kuijpers-Jagtman AM, et al. Timing and transplant materials for closure of alveolar clefts: a clinical comparison of 296 cases. Journal of Cranio-Maxillofacial Surgery 1993;21(4):143-8.

[12] Kindelan J, Roberts-Harry D. A 5-year post-operative review of secondary alveolar bone grafting in the Yorkshire region. Br J Orthod 1999;26(3):211-7.

[13] Sandy JR. Clinical standards advisory group cleft lip report. Br Den J 1998;185(8):378.

[14] Williams AC, Bearn D, Mildinhall S, et al. Cleft lip and palate care in the United Kingdom--the Clinical Standards Advisory Group (CSAG) Study. Part 2: dentofacial outcomes and patient satisfaction. The Cleft PalateCraniofacial Journal 2001;38(1):24-9. 
[15] Boyne PJ, Sands NR. Combined orthodontic - surgical management of residual palato- alveolar cleft defect. Am J Orthod 1976;70(1):20-37.

[16] Sillman JH. Dimensional changes of the dental arches: longitudinal study from birth to 25 years. Am J Orthod 1964;50(11):824-42.

[17] Enemark H, Sindet-Pedersen S, Bundgaard M. Long-term results of secondary bone grafting of alveolar clefts. J Oral Maxillofac Surg 1987;45(11):913-9.

[18] Lilja J, Kalaaji A, Friede H, et al. Combined bone grafting and delayed closure of the hard palate in patients with unilateral cleft lip and palate: facilitation of lateral incisor eruption and evaluation of indicators for timing of the procedure. Cleft Palate Craniofac J 2000;37(1):98-105.

[19] Enemark H, Jensen J, Bosch C. Mandibular bone graft material for reconstruction of alveolar cleft defects: longterm results. Cleft Palate Craniofac J 2001;38(2):155-63.

[20] Sindet-Pedersen S, Enemark H. Management of impacted teeth in congenital clefts. In: Alling CC, Helfrick JF, Alling RD, eds. Impacted teeth. Philadelphia: Saunders 1993:344-52.

[21] Rawashdeh MA, Telfah H. Secondary alveolar bone grafting: the dilemma of donor site selection and morbidity. Br J Oral Maxillofac Surg 2008;46(8):665-70.

[22] Ilankovan V, Stronczek M, Telfer M, et al. A prospective study of trephined bone grafts of the tibial shaft and iliac crest. Br J Oral Maxillofac Surg 1998;36(6):434-9.

[23] Rahpeyma A, Khajehahmadi S. Chin bone graft for maxillary alveolar cleft: indications and limitations. J Craniofac Surg 2014;25(5):1650-2.

[24] Misch CE, Dietch FM. Keys to bone grafting and bone grafting materials. In: Misch CE, ed. Contemporary implant dentistry. St. Louis: Mosby Elsevier 2008:839-68.

[25] Bajaj AK, Wongworawat AA, Punjabi A. Management of alveolar clefts. J Craniofac Surg 2003;14(6):840-6.

[26] Rodella LF, Favero G, Labanca M. Biomaterials in maxillofacial surgery: membranes and grafts. Int J Biomed Sci 2011; 7(2):81-8.
[27] Steven MR, Emam HA. Dental implant prosthetic rehabilitation: allogeneic grafting/bone graft substitutes in implant dentistry. In: Bagheri SC, Bell RB, Khan HA, eds. Current therapy in oral and maxillofacial surgery. St. Louis, Mo: Elsevier Saunders 2011:157-62.

[28] Kinsella CR, Cray JJ, Durham EL, et al. Recombinant human bone morphogenetic protein-2-induced craniosynostosis and growth restriction in the immature skeleton. Plast Reconstr Surg 2011;127(3):1173-81.

[29] Francis CS, Mobin SSN, Lypka MA, et al. rhBMP-2 with a demineralized bone matrix scaffold versus autologous iliac crest bone graft for alveolar cleft reconstruction. Plast Reconstr Surg 2013;131(5):1107-15.

[30] Lilja J. Alveolar bone grafting. Indian J Plast Surg 2009;42 Suppl:S110-5.

[31] Trindade IK, Mazzottini R, da Silva Filho OG, et al. Longterm radiographic assessment of secondary alveolar bone grafting outcomes in patients with alveolar clefts. Oral Surg Oral Med Oral Pathol Oral Radiol Endod 2005;100(3):271-7.

[32] Witherow H, Cox S, Jones E, Carr R, et al. A new scale to assess radiographic success of secondary alveolar bone grafts. Cleft Palate Craniofac J 2002;39(3):255-60.

[33] Hudak KA, Hettinger P, Denny AD. Cranial bone grafting for alveolar clefts: a 25-year review of outcomes. Plast Reconstr Surg 2014;133(5):662e-8e.

[34] Jain A, Nimonkar P, Bhola N, et al. Does hamulotomy during palatoplasty have any effect on hearing ability in nonsyndromic cleft palate patients? A prospective, single blind, comparative study. Scientifica (Cario) 2016;2016:1-6.

[35] Sabarinath VP, Hazarey PV, Ramakrishna Y, et al. Caring for cleft lip and palate infants: impression procedures and appliances in use. J Indian Prosthod Soc 2009;9(2):76-80.

[36] Sabarinath VP, Radhakrishnan V, Hazarey PV, et al. Alternative approaches to managing the cleft alveolus. J Clin Pediatr Dent 2013;38(1):89-93. 